\title{
Laryngeal abductor paralysis-intellectual disability syndrome
}

INSERM

\section{Source}

INSERM. (1999). Orphanet: an online rare disease and orphan drug data base. Laryngeal abductor paralysis-intellectual disability syndrome. ORPHA:2375

Laryngeal abductor paralysis-intellectual disability syndrome is characterised by congenital and permanent laryngeal abductor paralysis, associated, in the majority of cases, with intellectual deficit. It has been described in several families. X-linked inheritance is likely. 